\title{
Rasta Disease of Tomato in Ghana is Caused by the Pospiviroids Potato spindle tuber viroid and Tomato apical stunt viroid
}

\author{
Ozgur Batuman, ${ }^{1,+}$ Ö. Cem Çiftçi, ${ }^{2}$ Michael K. Osei, ${ }^{3}$ Sally A. Miller, ${ }^{4}$ Maria R. Rojas, ${ }^{5}$ and Robert L. Gilbertson ${ }^{5}$ \\ ${ }^{1}$ Department of Plant Pathology, Southwest Florida Research and Education Center, University of Florida-IFAS, Immokalee, FL \\ 34142, U.S.A.; ${ }^{2}$ Molecular Biology, Genetics and Bioengineering, Sabanc1 University, Istanbul, Turkey; ${ }^{3}$ CSIR-Crops Research \\ Institute, P.O. BOX 3785, Kumasi, Ghana; ${ }^{4}$ Department of Plant Pathology, The Ohio State University, Wooster, OH 44691, U.S.A.; \\ and ${ }^{5}$ Department of Plant Pathology, University of California-Davis, Davis, CA 95616, U.S.A.
}

\begin{abstract}
Rasta is a virus-like disease of unknown etiology affecting tomato (Solanum lycopersicum) plants in Ghana. Symptoms include stunting; epinasty, crumpling, and chlorosis of leaves; and necrosis of leaf veins, petioles, and stems. Leaf samples with rasta symptoms were collected from commercial tomato fields in Ghana in October 2012 and applied to FTA cards, and RNA extracts were prepared. Reverse-transcription polymerase chain reaction (RT-PCR) tests with primers for Columnea latent viroid, which causes rasta-like symptoms in tomato plants in Mali, were negative, whereas tests with degenerate viroid primer pairs were inconclusive. However, tomato seedlings (Early Pak 7) mechanically inoculated with RNA extracts of 10 of 13 samples developed rasta-like symptoms. In RT-PCR tests with RNA from leaves of the 10 symptomatic seedlings and primers for Potato

spindle tuber viroid (PSTVd) or Tomato apical stunt viroid (TASVd), the expected size (approximately $360 \mathrm{bp}$ ) of DNA fragment was amplified from eight and two seedlings, respectively. Sequence analyses confirmed that these fragments were from PSTVd and TASVd isolates, and revealed a single PSTVd haplotype and two TASVd haplotypes. The PSTVd and TASVd isolates from Ghana had high nucleotide identities $(>94 \%)$ with isolates from other geographic regions. In a host range study, PSTVd and TASVd isolates from Ghana induced rasta symptoms in the highly susceptible tomato cultivar Early Pak 7 and mild or no symptoms in Glamour, and symptomless infections in a number of other solanaceous species PSTVd and TASVd isolates were seed associated and possibly seed transmitted.
\end{abstract}

Tomato is a major vegetable crop throughout the Sudano-Sahelian zone of West Africa but production is limited by various abiotic and biotic constraints (Perez et al. 2017). Diseases and pests can cause substantial losses to tomato production in West Africa, particularly for smallholder farmers. Economically important tomato diseases are caused by soilborne pathogens such as Ralstonia solanacearum (bacterial wilt), Fusarium oxysporum f. sp. lycopersici (Fusarium wilt), Sclerotium rolfsii (Southern blight), and Meloidogyne spp. (root knot); a complex of foliar pathogens, including Xanthomonas spp. (bacterial spot), Phytophthora infestans (late blight), and Septoria lycopersici (Septoria blight); and mosaic, crumpling, and distortion of leaves caused by potyviruses Tomato mosaic virus (TMV) and Cucumber mosaic virus (CMV) (Lamptey et al. 2013; Perez et al. 2017). Over the past 20 years, leaf curl and yellow leaf curl diseases, caused by a complex of whitefly-transmitted begomoviruses (genus Begomovirus, family Geminiviridae), have emerged as a major disease constraint on tomato production in West Africa (Chen et al. 2009; Leke et al. 2015; Perez et al. 2017; Zhou et al. 2008). However, over the past 10 years, tomato production in a number of West African countries has been affected by a virus-like disease of unknown etiology that is characterized by stunting (shortened internodes and a rosette appearance of infected plants); leaf epinasty, crumpling, and chlorosis; necrosis of leaf veins, petioles, and stems;

\section{${ }^{\dagger}$ Corresponding author: O. Batuman; E-mail: obatuman@ufl.edu}

Funding: This research was supported by a grant from the Integrated Pest Management Innovation Laboratory (formerly the Integrated Pest Management Collaborative Research Support Program), made possible by the United States Agency for International Development and the generous support of the American people through United States Agency for International Development Cooperative Agreement EPPA-00-04-00016-00

The author(s) declare no conflict of interest.

Accepted for publication 10 January 2019.

(c) 2019 The American Phytopathological Society and production of small quantities of small-sized fruit. In Mali, these symptoms were shown to be caused by the viroid Columnea latent viroid (CLVd) (Batuman and Gilbertson 2013).

Viroids are small, infectious, unencapsidated, circular, singlestranded RNAs that depend entirely on host plant factors for replication and spread. Viroids cause numerous economically important diseases of annual and perennial crops, including tomato (Solanum lycopersicum), potato (S. tuberosum), pepper (Capsicum annuum), citrus (Citrus spp.), grapevine (Vitis vinifera), and numerous ornamental plants (Diener 1971, 1979; Sanger et al. 1976). The genome of viroids does not encode for any proteins, and replication does not involve a helper virus. The size of the genome ranges from 246 to 401 nucleotides (nt), which makes viroids among the smallest known infectious disease agents. Viroids replicate in the nucleus (members of the family Pospiviroidae) or in plastids (members of the family Avsunviroidae) of infected cells (Branch and Robertson 1984; Daros et al. 1994; Di Serio et al. 2014; Ding 2009; Flores et al. 2000, 2009). A number of comprehensive reviews on viroids have been published (Diener 2003; Ding 2009; Flores et al. 2005, 2014; Gucek et al. 2017; Hull 2013; Navarro et al. 2012; Tabler and Tsagris 2004).

Disease symptoms induced by viroids range from extremely severe (e.g., stunting, shortened internodes, and distorted growth; epinasty, crumpling, and chlorosis of leaves; and necrosis of leaf veins, petioles, and stems) to mild or no symptoms (e.g., symptomless infections in many ornamental plants). Symptomless hosts complicate viroid detection and host range determination, and may serve as reservoirs for infection of economically important crops (Bar-Joseph 2003; De la Peña and Flores 2002; Fadda et al. 2003; Matsushita and Tsuda 2015; Murcia et al. 2011; Singh et al. 1992; Spieker 1996; Verhoeven et al. 2015). The mechanisms underlying the wide range of symptoms induced in plants infected by viroids are not well understood but may involve viroid-induced posttranscriptional gene silencing of host genes (Adkar-Purushothama et al. 2015; Pallas et al. 2012).

Plant-to-plant transmission of viroids occurs by grafting; mechanically, including by contact; and via seed and pollen (Hadidi et al. 1997; Kryczyński et al. 1988; Mink 1993; Semancik and Szychowski 1992; Singh 1970; Szychowski et al. 1988; Wallace and Drake 1962). There is also increasing evidence that some insects and even 
animals may facilitate the transmission of viroids through nonspecific contact (Antignus et al. 2007; Cohen et al. 2005; De Bokx and Piron 1981; Matsuura et al. 2010; Van Bogaert et al. 2016).

Currently, 32 viroid species are recognized by the International Committee on Taxonomy of Viruses. Most of these $(n=28)$ belong to the family Pospiviroidae, which contains five genera, including Pospiviroid (9 species), Hostuviroid (2 species), Cocadviroid (4 species), Apscaviroid (10 species) and Coleoviroid (3 species) (Di Serio et al. 2014). With the exception of the Iresine viroid 1, eight of nine viroid species in the genus Pospiviroid infect and cause disease symptoms in tomato: Chrysanthemum stunt viroid, Citrus exocortis viroid, CLVd, Mexican papita viroid, Pepper chat fruit viroid, Potato spindle tuber viroid (PSTVd), Tomato apical stunt viroid (TASVd), Tomato chlorotic dwarf viroid, and Tomato planta macho viroid. Moreover, these viroids induce similar symptoms in tomato (e.g., stunting and distorted growth; chlorosis, crumpling, distortion, and epinasty of leaves; necrosis of leaf veins, petioles, and stems; and small-sized fruit), can substantially reduce yields, and pose major regulatory concerns (Antignus et al. 2002; Batuman and Gilbertson 2013; Galindo et al. 1982; Gast et al. 1996; Mishra et al. 1991; Singh et al. 1999; Verhoeven and Roenhorst 2010; Verhoeven et al. 1998, 2004, 2009; Walter 1987). Over the past two decades, outbreaks of pospiviroids in tomato and pepper have been reported causing economic losses from many countries of the world, including Australia, China, the Dominican Republic, Israel, India, Japan, New Zealand, Thailand, and several countries in North and South America and Europe (Antignus et al. 2002; Candresse et al. 2010; Hailstones et al. 2003; Lebas et al. 2005; Ling and Bledsoe 2009; Ling and Sfetcu 2010; Ling and Zhang 2009; Ling et al. 2009, 2013, 2014; Matsushita et al. 2008; Mishra et al. 1991; Navarro et al. 2009; Parrella and Numitone 2014; Pearson et al. 2006; Reanwarakorn et al. 2011; Singh et al. 1993; Verhoeven et al. 2004). In Africa, the first viroid reported to infect and cause yield loss in tomato was TASVd (Walter 1981, 1987), and it was recently reported infecting tomato plants in greenhouse production in Senegal (Candresse et al. 2007). More recently, CLVd was reported causing severe symptoms in tomato plants in open fields in Mali (Batuman and Gilbertson 2013). There also have been unconfirmed reports of PSTVd
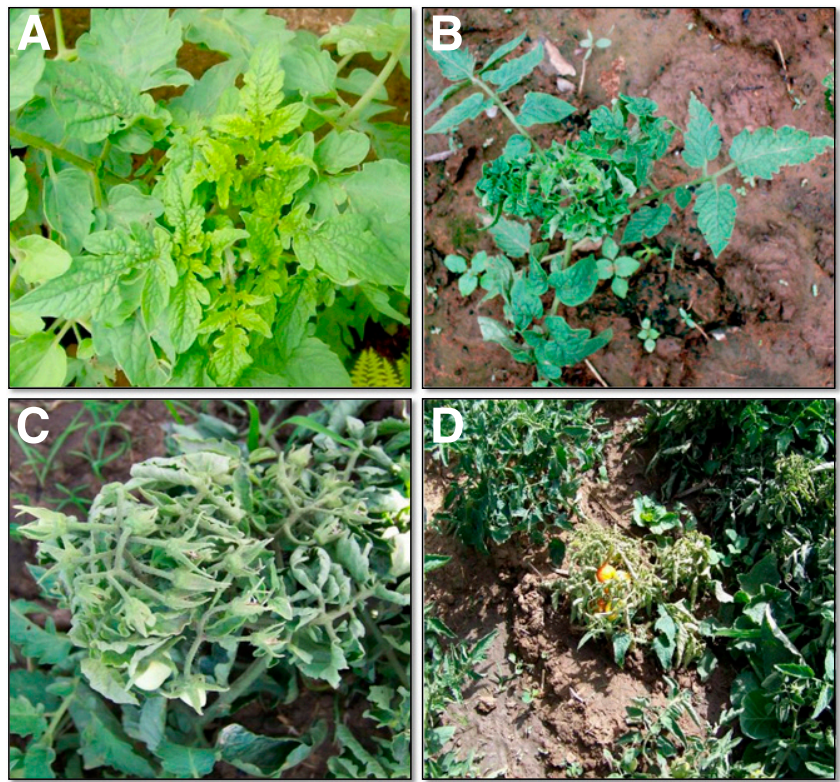

Fig. 1. Symptoms of rasta disease in commercial tomato fields in Ghana and Mali. A, Initial symptoms of shortened internodes and epinasty and crumpling of leaves (Ghana). B, More severe symptoms in a plant at the vegetative stage of growth, including stunting and a bushy or rosette appearance and crumpling and down curling of leaves (Ghana). C, Severe symptoms in a plant at the reproductive stage of growth, including severe stunting, distorted growth, and a bunchy or rosette appearance; chlorosis and curling of leaves; and irregular flower formation (Ghana). D, Extreme stunting, chlorosis, and necrosis of a plant at the reproductive stage of growth, with production of a few small-sized fruit (Mali). associated with potato production in Egypt, Nigeria, and South Africa (OEPP/EPPO 2014).

As part of the United States Agency for International Development (USAID) Integrated Pest Management Collaborative Research Support Program (IPM-CRSP), now the IPM Innovation Laboratory, virus disease surveys of commercial tomato fields in multiple countries of West Africa (e.g., Benin, Burkina Faso, Ghana, Mali, Niger, Senegal, and Togo) have revealed viroid-like disease symptoms in some fields. In Ghana, this disease is locally referred to as rasta due to the unusual form of symptomatic plants. Here, we report that the rasta disease of tomato in Ghana is caused by PSTVd and TASVd, and that the symptoms caused by these two viroids, as well as CLVd, are indistinguishable. We also determined biological and genetic properties of PSTVd and TASVd isolates from Ghana, including their relationship with viroids from other geographic regions, host range, and association with seed.

\section{Materials and Methods}

Survey of commercial tomato fields in Ghana for rasta disease. A survey of commercial tomato fields in two tomato-producing regions of Ghana-Ashanti (including the towns of Agogo and Akumadan) and Brong Ahafo (including the town of Tuobodom)-was conducted from 29 to 31 October 2012, a time of year that corresponds to the "minor" rainy season. These were relatively small fields ( 0.5 to $2.0 \mathrm{ha}$ ) and were planted with the local varieties petofake and akoma. In total, 12 commercial fields were surveyed: 8 in Ashanti (5 from around Agogo [AG1 to AG5] and 3 from around Akumadan [AK1 to AK3]) and 4 in Brong Ahafo (all around Tuobodom [T1 to T4]). Each field was walked in a zig-zag pattern, 100 plants per field were visually examined, and the incidence of rasta-like disease symptoms in each field was estimated. Leaf samples were collected from one to three plants with rasta-like symptoms (i.e., some combination of stunting; epinasty, crumpling, and chlorosis of leaves; and necrosis of leaf veins, petioles, and stems) (Fig. 1) per field, placed in plastic bags, and returned for processing at local accommodations.

Tests conducted for known tomato-infecting viruses and application of rasta samples onto FTA cards. In a previous study of rasta-like symptoms in tomato plants in open field production in Mali, we demonstrated that these symptoms were not caused by a range of viruses or microorganisms (Batuman et al. 2013). Therefore, in the present study, we tested representative leaf samples with rasta symptoms only for infection by common tomato-infecting viruses, including CMV, TMV, Tomato spotted wilt virus (TSWV), and begomoviruses. For CMV, TMV, and TSWV, this was done with lateral-flow devices as described by Lamptey et al. (2013), whereas begomovirus infection was detected by squash blot hybridization with a general begomovirus DNA probe as described by Perez et al. (2017). Moreover, as part of this survey, we also collected leaf samples from plants with (i) symptoms of mosaic, crumpling, and distorted growth and (ii) stunting and curling, distortion, and yellowing of leaves (begomovirus symptoms). In the present study, these served as positive controls for lateral-flow and squash blot hybridization tests, respectively.

For application of samples onto FTA cards, approximately 2-by2-cm pieces of leaf tissue were squashed directly onto the designated areas on FTA cards in duplicate (Whatman, Kent, U.K.), as described in the FTA Plant Starter Kit (GE Healthcare Bio-Sciences, Pittsburgh, PA, U.S.A.). The FTA cards were allowed to dry at room temperature and subsequently transported to the University of California-Davis (UC Davis, CA, U.S.A.), where they were maintained at room temperature.

Nucleic acid extraction from FTA cards. No more than 5 days after being brought to UC Davis, total RNA was extracted from the samples on the FTA cards. Total RNA was extracted from squashes of leaf samples on FTA cards as previously described (Ndunguru et al. 2005). For each sample, total RNA was extracted from three filter paper discs, $2 \mathrm{~mm}$ in diameter, which were excised from the green-stained application area with a sterile cork borer. The three filter paper disks were placed into a 1.5-ml Eppendorf tube, and $500 \mu \mathrm{l}$ of freshly prepared RNA extraction buffer $(10 \mathrm{mM}$ Tris- $\mathrm{HCl}$, 
pH 8.0; 0.1 mM EDTA; RNase Out [Invitrogen, Carlsbad, CA, U.S.A.] at $800 \mathrm{U} / \mathrm{ml}$; glycogen at 200 to $250 \mu \mathrm{g} / \mathrm{ml}$, and $2 \mathrm{mM}$ dithiothreitol [DTT]) was added. The tubes were kept on ice for $30 \mathrm{~min}$, with mixing every $5 \mathrm{~min}$. The filter paper disks were pressed against the inside of the tube, and then removed with a sterile pipette tip. Total RNA was precipitated by adding 0.1 volume of $3 \mathrm{M}$ sodium acetate $(\mathrm{pH}$ 5.2 ) and an equal volume of ice-cold $100 \%$ isopropanol and mixing well. The tubes were then kept at $-80^{\circ} \mathrm{C}$ for $30 \mathrm{~min}$. The RNA was recovered by centrifugation at $10,000 \times g$ for $10 \mathrm{~min}$, washed with ice-cold $75 \%$ ethanol, dried, and suspended in $30 \mu \mathrm{l}$ of RNase-free water. These RNA extracts were used in reverse-transcription polymerase chain reaction (RT-PCR) tests and for rub inoculation of tomato seedlings (see below).

Viroid cDNA synthesis and RT-PCR. To generate cDNA of fulllength viroid genomes, RT-PCR and random hexamer primers (Invitrogen, Carlsbad, CA, U.S.A.) and SuperScript II RT (Invitrogen) were used. The RT-PCR was performed in a total volume of $20 \mu \mathrm{l}$ with $3 \mu \mathrm{l}$ of RNA extract, $1 \mu \mathrm{l}$ of $10 \mathrm{mM}$ random hexamers, $1 \mu \mathrm{l}$ (100 U) of SuperScript II, $1 \mu \mathrm{l}$ of dNTP Mix (10 mM each), $2 \mu l$ of $0.1 \mathrm{M}$ DTT and $5 \mu \mathrm{l}$ of $5 \times$ First-Strand Buffer. The RT-PCR was performed at $42{ }^{\circ} \mathrm{C}$ for $45 \mathrm{~min}$. Next, the PCR was performed in a final volume of $25 \mu \mathrm{l}$ with $3 \mu \mathrm{l}$ of the cDNA from the RT-PCR, $1 \mu l$ of dNTP Mix (10 mM each), $1 \mu l$ of each primer $(10 \mathrm{mM})$, $0.5 \mu \mathrm{l}$ of $25 \mathrm{mM} \mathrm{MgCl}, 0.2 \mu \mathrm{l}(0.5 \mathrm{U})$ of iProof High-Fidelity DNA polymerase (Bio-Rad, Richmond, CA, U.S.A.), and $5 \mu \mathrm{l}$ of $5 \times$ HF buffer. The PCR parameters were as follows: denaturation at $98^{\circ} \mathrm{C}$ for $2 \mathrm{~min} ; 30$ cycles of $98^{\circ} \mathrm{C}$ for $20 \mathrm{~s}, 60^{\circ} \mathrm{C}$ for $20 \mathrm{~s}$, and $72^{\circ} \mathrm{C}$ for $30 \mathrm{~s}$; and a final extension of $72^{\circ} \mathrm{C}$ for $5 \mathrm{~min}$. Viroid primer pairs used in the PCR were either from previously published studies or were newly designed based on viroid sequences in the GenBank and those generated in the present study (Table 1). PCR products were analyzed by agarose gel electrophoresis and selected PCRamplified cDNA fragments were gel-purified with a Qiaquick PCR Purification Kit (Qiagen, Valencia, CA, U.S.A.).

Sequence and phylogenetic analyses. Gel-purified PCRamplified DNA fragments were directly sequenced at the UC Davis
Sequencing Facility with the primer pairs used in the PCR. Sequences were initially analyzed with the BioEdit program, version 7.05 (http://www.mbio.ncsu.edu/BioEdit/bioedit.html), and compared with those in GenBank with the BLASTn program (Altschul et al. 1990), available at the National Center for Biotechnology Information (https://www.ncbi.nlm.nih.gov/BLAST/). Sequences were aligned with Clustal W (Thompson et al. 1994). Phylogenetic trees were constructed from the Clustal $\mathrm{W}$-aligned sequences with MEGA, version 6 (Tamura et al. 2013), with the neighbor-joining method (Saitou and Nei 1987) to conduct the bootstrap analysis (1,000 replicates).

Inoculation of tomato seedlings with RNA extracts and various plant species with sap. RNA extracts from samples on FTA cards were rub inoculated onto the first true leaves of 3- to 4-week-old tomato seedlings (Early Pak 7), which had been dusted with Celite. Prior to inoculation, $20 \mu \mathrm{l}$ of each RNA extract was diluted in $80 \mu \mathrm{l}$ of sap inoculation buffer $(0.01 \mathrm{M}$ potassium phosphate buffer, $\mathrm{pH}$ 7.2) to make the RNA inoculation preparation. Two tomato seedlings (Early Pak 7) were each mechanically (rub) inoculated with $50 \mu \mathrm{l}$ of inoculation preparation for each RNA extract per experiment. Three independent experiments were performed, such that six seedlings in all were inoculated for each extract. The negative control was an RNA extract prepared from leaf samples from uninfected tomato plants squashed on FTA cards.

For sap-transmission experiments, tomato leaf tissue was ground in sap inoculation buffer at a 1:10 (wt/vol) ratio. This sap preparation was rub inoculated onto Celite-dusted leaves of seedlings of tomato and other plant species (see below). The negative control was sap prepared from leaf tissue of uninfected tomato plants, and the positive control was sap prepared from leaf tissue of tomato plants infected with an isolate of CLVd from Mali (Mali OB1 2011). Plants were maintained in a growth chamber at $25^{\circ} \mathrm{C}, 60 \%$ relative humidity, and $16 \mathrm{~h}$ of light. Symptom development was monitored at 7, 10, $14,21,28$, and, in some cases, 50 to 180 days postinoculation (dpi).

Host range experiments. Viroid isolates were maintained in tomato plants (Early Pak 7) by sap transmission as described above.

Table 1. List of primers used for detection of pospiviroids by reverse-transcription polymerase chain reaction

\begin{tabular}{|c|c|c|c|}
\hline Name $^{\mathbf{a}}$ & Position & Sequence & Reference \\
\hline Pospiviroid F & $90-109$ & ATT AAT CCC CGG GGA AAC CTG GAG & General primer pair for detection of pospiviroids (Bostan et al. 2004) \\
\hline Pospiviroid R & $282-260$ & AGC TTC AGT TGT TTC CAC CGG GT & \\
\hline Pospi1-RE & $261-283$ & AGC TTC AGT TGT (T/A)TC CAC CGG GT & General primer pair for detection of pospiviroids (Verhoeven et al. 2004) \\
\hline Pospi1-FW & $86-102$ & GGG ATC CCC GGG GAA AC & $\ldots$ \\
\hline Vid-FW & $355-16$ & TTC CTC GGA ACT AAA CTC GTG & General primer pair for detection of pospiviroids (Verhoeven et al. 2004) \\
\hline Vid-RE & 336-354 & CCA ACT GCG GTT CCA AGG G & \\
\hline MTTVd-R & $92-75$ & GGG GAT CCC TGA AGC GCT CCT & General primer for detection of pospiviroids (Ling and Zhang 2009) \\
\hline OB Viroid F & $85-106$ & CTT CAG GGA TCC CCG GGG AAA C & $\begin{array}{l}\text { General primer pair for detection of pospiviroids designed based on } \\
\text { an alignment of sequences of tomato viroids }\end{array}$ \\
\hline OB Viroid $\mathrm{R}$ & $291-268$ & AGC TTC AGT TGT TTC CAC CGG GTA & \\
\hline TASVd F & $109-125$ & GGG GAA ACC TGG AGG AA & $\begin{array}{l}\text { Tomato apical stunt viroid (TASVd)-specific primer pair (Candresse } \\
\text { et al. 2007) }\end{array}$ \\
\hline TASVd R & $108-91$ & GGG GAT CCC TGA AGG AC & \\
\hline TASVd FOB & $262-285$ & GCT TCT CTC TGG AGA CTA CCC GGT & $\begin{array}{l}\text { TASVd-specific abutting primer pair designed based on an alignment } \\
\text { of sequences of TASVd isolates }\end{array}$ \\
\hline TASVd ROB & $261-237$ & TCC GGG CGA GGG CCG AAG ACC T & \\
\hline pCLVR4 & $103-121$ & GGG GCA ACT CAG ACC GAG C & Columnea latent viroid (CLVd)-specific primer pair (Spieker 1996) \\
\hline pCLV4 & $81-102$ & GGG GCT CCT GAG ACC GCT CTT G & $\ldots$ \\
\hline CLVd FOB & $273-292$ & ACC GGT GGC ATC ACC GAG TT & $\begin{array}{l}\text { CLVd-specific abutting primer pair designed based on an alignment } \\
\text { of CLVd sequences }\end{array}$ \\
\hline CLVd ROB & $272-253$ & CGC GTC AGA ACC TGC GCT GG & \\
\hline PSTVd FOB1 & $106-125$ & CCT GGA GCG AAC TGG CAA AA & $\begin{array}{l}\text { Potato spindle tuber viroid (PSTVd)-specific abutting primer pair } \\
\text { designed based on an alignment of sequences of PSTVd isolates }\end{array}$ \\
\hline PSTVd ROB 1 & $105-85$ & TTT CCC CGG GGA TCC CTG AAG & \\
\hline PSTVd FOB2 & $268-289$ & CCC GGT GGA AAC AAC TGA AGC T & $\begin{array}{l}\text { PSTVd-specific abutting primer pair based on an alignment of sequences } \\
\text { of PSTVd isolates }\end{array}$ \\
\hline PSTVd ROB2 & $267-247$ & TAG TAG CCG AAG CGA CAG CGC & \\
\hline
\end{tabular}

${ }^{\mathrm{a}} \mathrm{OB}=$ primers that were designed in the present study based on alignments of sequences of the viroids from Ghana and from sequences retrieved from GenBank. $\mathrm{FOB}$ and $\mathrm{ROB}=$ the abutting primers designed in the present study to direct the amplification of the complete viral genome based on alignments of sequences of the viroids from Ghana and those from GenBank. 
The host range of PSTVd isolates OB25 and OB36 and TASVd isolates OB1 and OB4 from Ghana was determined by rub inoculation of $C$. annuum L. 'Yolo Wonder', Chenopodium quinoa (Willd.), $C$. amaranticolor L., Cucurbita pepo 'Small Sugar', Cucumis sativus 'Emparator' and 'Poinsett 76', Datura stramonium L., S. lycopersicum 'Early Pak 7' and 'Glamour', Nicotiana benthamiana, N. tabacum L. 'Havana' and 'Glurk', N. glutinosa, and Phaseolus vulgaris 'Othello' and 'Topcrop' with sap prepared from leaf tissue of viroid-infected Early Pak 7 tomato plants, as described above. The positive control was sap prepared from tomato leaves infected with the isolate of CLVd from Mali, whereas the negative control was plants mock inoculated with inoculation buffer alone. In each of three independent experiments, three seedlings of each species were inoculated with the four treatments (CLVd, PSTVd, TASVd, and buffer alone), for a total of nine plants inoculated per treatment. Inoculated plants were maintained at $25^{\circ} \mathrm{C}$ in a growth chamber for $180 \mathrm{dpi}$ and symptom development was monitored weekly. Two weeks after inoculation and at the end of the experiment, viroid infection was determined by RT-PCR tests with total RNA extracted from newly emerged leaves and the appropriate viroid-specific primer pair (Table 1), as previously described.

Detection of isolates of PSTVd and TASVd from Ghana in tomato leaves, fruit, seed, and seedlings. For the experiment to detect the infection of tomato organs with isolates of PSTVd and TASVd from Ghana, tomato plants (Early Pak 7) were rub inoculated with sap prepared from leaves of tomato plants infected with PSTVd (isolates OB25 and OB36) or TASVd (isolates OB1 and OB4). The positive control was tomato plants (Early Pak 7) rub inoculated with sap prepared from leaves of tomato plants infected with the CLVd isolate from Mali, whereas the negative control was tomato plants (Early Pak 7) that were mock inoculated with inoculation buffer alone. This experiment was repeated three times with 8 plants inoculated per experiment (i.e., 24 plants inoculated with each of the PSTVd isolates, the TASVd isolates, the CLVd isolate, and buffer alone). By 15 dpi, all of the viroid-inoculated plants in each of the three experiments developed rasta-like symptoms. RNA was extracted from leaf and, when available, fruit tissues and seed with the Qiagen RNeasy kit (Qiagen) according to the manufacturer's instructions. For each plant, RNA was extracted from $100 \mathrm{mg}$ of leaf and fruit tissue and from 1 to 5 seeds. These seed were extracted from fruit harvested at 90 dpi and allowed to dry. The extracted RNA was used in RTPCR tests as previously described.

For the experiment to detect these viroids in seedlings emerging from viroid-infected seed, the remainder of the seed extracted from fruit harvested at 90 dpi from the 24 plants infected with the isolates of PSTVd or TASVd or mock inoculated were used in seed germination tests. In these tests, $<150$ healthy-appearing seed (i.e., not shriveled and discolored) from each treatment were placed on moist filter paper and allowed to germinate and produce hypocotyls and cotyledonary leaves. Hypocotyls and cotyledonary leaves of seedlings of all treatments were initially scored for the presence of necrotic lesions, and these were collected. In addition, 10 hypocotyls and cotyledonary leaves without necrotic lesions were randomly collected from each treatment. RNA was extracted from hypocotyls and cotyledonary leaves as described above and used in RT-PCR tests with PSTVd- and TASVd-specific primers to detect viroid infection.

\section{Results}

Rasta disease was widely distributed in the tomato-growing regions of Ashanti and Brong Ahafo but at low incidences. In the survey of commercial tomato fields conducted in Ghana from 29 to 31 October 2012, rasta-like symptoms were observed in 8 of 12 fields (Fig. 1A to C). Rasta-like symptoms were observed in fields in the Ashanti region, including three near Agogo (AG1, AG3, and AG4) and three near Akumadan (AK1, AK2 and AK3), and two fields near Tuobodom in the Brong Ahafo region (T1 and T3). Disease incidences in these eight fields ranged from 1 to $15 \%$. The mean incidence was $4 \%$, and the highest incidence was $15 \%$ in field AK3. Leaf samples with rasta-like symptoms were collected from 13 tomato plants: 2 from field AG1 and 1 each from fields AG3 and AG4 near Agogo; 3 from field AK3, 2 from field AK2, and 1 from field AK1 near Akumadan; and 2 from field T3 and 1 from field T1 near Tuobodom. Leaf samples were squashed onto FTA cards in Ghana, and RNA was extracted from these samples at UC Davis.

Tomato plants with rasta symptoms tested negative for infection by common tomato-infecting viruses. The 13 selected plants with rasta-like symptoms tested negative for infection with CMV, TMV, or TSWV based on results of lateral-flow tests conducted in Ghana. The results for TSWV were particularly important because some of the symptoms of rasta disease (e.g., stunting and chlorosis, crumpling, and necrosis of leaf veins and stems) can resemble those caused by this thrips-transmitted virus. These plants also tested negative for begomovirus infection based on results of squash blot hybridization analysis with a general begomovirus probe (data not shown). Further evidence that the rasta symptoms in these fields were distinct from those caused by viruses came from the detection of CMV in leaves with distortion and mosaic symptoms collected from fields AK1, T3, and T4; however, leaves with mosaic symptoms from other fields tested negative for CMV, TMV, and TSWV, suggesting a role for another virus. It is likely that these symptoms were caused by a potyvirus, which was subsequently associated with mosaic symptoms in tomato fields in the Ashani and Brong Ahafo regions (data not shown). Begomovirus infection was detected in plants with leaf curl and yellow leaf curl symptoms collected from all of these fields (Mater et al. 2015).

Rasta disease of tomato in Ghana is caused by PSTVd or TASVd. Because it was previously established that rasta-like symptoms in tomato in Mali are caused by CLVd (Fig. 1D) (Batuman and Gilbertson 2013), we hypothesized (i) that rasta disease in Ghana is caused by a viroid and (ii) that the viroid is CLVd. Results of RT-PCR tests with CLVd-specific primers (Table 1) were negative (i.e., no DNA fragments were amplified), whereas the expected-size DNA fragment (approximately $360 \mathrm{bp}$ ) was amplified in equivalent RT-PCR tests performed with RNA from leaves of CLVd-infected tomato plants (positive control). Thus, the rasta-like symptoms in the tomato plants sampled in Ghana were not caused by CLVd, thereby rejecting the second hypothesis but not ruling out the involvement of other viroids. RT-PCR tests were next performed with these RNA extracts and four degenerate viroid primer pairs (Table 1). The results of these tests were negative or inconsistent (i.e., multiple DNA fragments were amplified).

To further test the hypothesis of a viroid etiology for rasta disease in Ghana, we next utilized a biological indicator (tomato seedlings of the highly susceptible cultivar Early Pak 7) to detect viroid RNA in the RNA extracts prepared from the FTA cards with the 13 leaf samples with rasta-like disease symptoms. Tomato seedlings rub inoculated with RNA preparations of 10 of 13 of these samples were stunted and developed severe leaf epinasty, crumpling, and vein necrosis by 7 to $15 \mathrm{dpi}$ (Fig. 2A to D). Moreover, these symptoms were similar to those observed in tomato plants with rasta disease in Ghana (Fig. 1A to C). Tomato seedlings inoculated with RNA preparations of the other three samples did not develop symptoms, and appeared similar to those inoculated with RNA preparations of leaf tissue collected from uninfected tomato plants (negative control). Thus, as previously demonstrated by Batuman et al. (2013), the infectious nature of these RNA extracts and the subsequent development of rasta-like symptoms in inoculated tomato seedlings supported the hypothesis of a viroid etiology for rasta disease in Ghana.

To identify the putative viroids causing the rasta-like symptoms in the tomato seedlings inoculated with the RNA preparations of the 10 rasta samples, RNA was extracted from symptomatic leaves and used in RT-PCR tests with CLVd-specific and degenerate primer pairs (Table 1). Consistent with results obtained with RT-PCR tests performed with RNA extracts from these 10 samples applied to FTA cards, RT-PCR tests with the CLVd-specific primer pairs were negative, and inconsistent results were obtained in equivalent RT-PCR tests with viroid degenerate primer pairs. The expected-size DNA fragment (approximately $360 \mathrm{bp}$ ) was amplified in equivalent RT-PCR tests with an RNA extract prepared from leaves of a 
CLVd-infected tomato plant and the CLVd-specific primers (positive control). These results were consistent with CLVd not being the cause of the rasta disease samples from Ghana, and also suggested that the failure to amplify the target viroid fragments with the viroid degenerate primer pairs was not due to problems with the RNA extraction or the RT-PCR methods.

We next performed RT-PCR tests with the RNA extracts from the symptomatic seedlings and viroid-specific primer pairs developed in the present study for detection of PSTVd (PSTVd-FOB1 and -ROB1) and TASVd (TASVd-FOB and -ROB) (Table 1). These abutting primer pairs were designed to direct the amplification of the complete genome (approximately $360 \mathrm{nt}$ ) of these viroids. Here, we focused on PSTVd and TASVd for these tests based on previous reports of these viroids infecting tomato and potato crops in other countries of Africa (Candresse et al. 2010; OEPP/EPPO 2014; Walter 1981, 1987). In the RT-PCR tests with the PSTVd primer pair, the expected-size DNA fragment (approximately $360 \mathrm{bp}$ ) was amplified from RNA extracts of symptomatic leaves of tomato seedlings inoculated with RNA preparations of eight of the rasta samples. These included the two samples from Agogo, five from Akumadan, and one from Tuobodom. In equivalent RT-PCR tests with the TASVd primer pair, the expected-size DNA fragment (approximately $360 \mathrm{bp}$ ) was amplified from RNA extracts of symptomatic leaves of seedlings inoculated with RNA preparations of the other two rasta samples, one each from Akumadan and Tuobodom. There were no mixed infections (i.e., both viroids detected in the same seedling). Selected DNA fragments amplified with the PSTVd or TASVd primer pairs were directly sequenced, and sequence analysis results confirmed their identity as PSTVd and TASVd fragments, respectively (data not shown). Together, these results indicate that rasta disease of tomato in Ghana is caused by PSTVd or TASVd.

Analysis of the complete nucleotide sequences of isolates of TASVd and PSTVd from Ghana. The complete nucleotide sequences of four PSTVd isolates-one from Agogo (OB21), one from Akumadan (OB25), and two from Tuobodom (OB27 and OB36, each from a different infected seedling)-were determined from PCR-amplified cDNA fragments. The genomes of these four PSTVd isolates are $358 \mathrm{nt}$, and the sequences are identical. Thus, the consensus sequence was deposited in GenBank (accession MG132059).
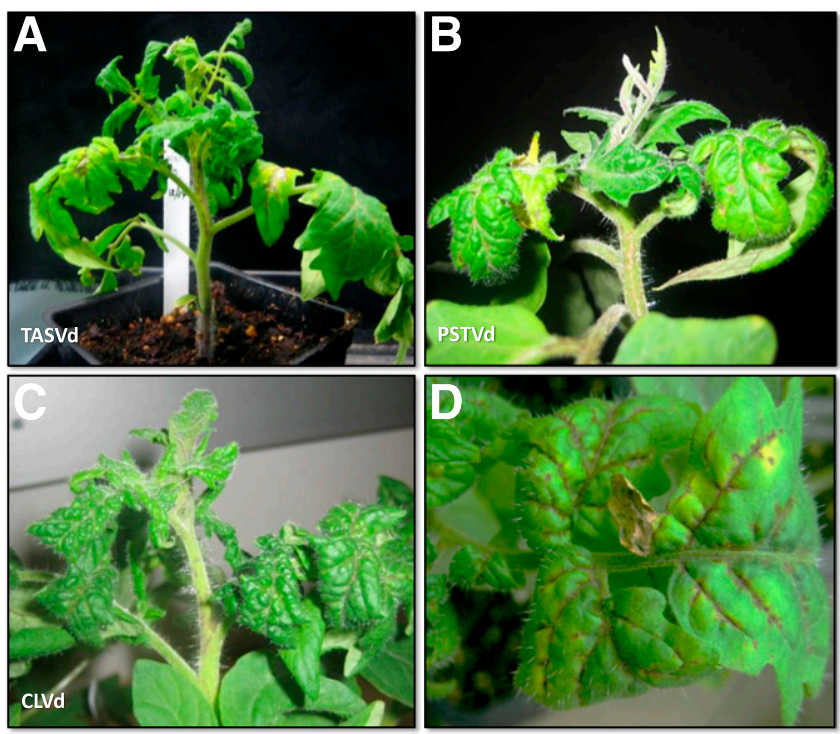

Fig. 2. Rasta-like disease symptoms of stunted and distorted growth and epinasty, crumpling, and vein necrosis of leaves induced in tomato plants (Early Pak 7) by $\mathbf{A}$, Tomato apical stunt viroid (TASVd); B, Potato spindle tuber viroid (PSTVd); and C, Columnea latent viroid (CLVd). Plants were photographed 15 days after inoculation with RNA extracts from an FTA card with a leaf squash of a tomato plant with symptoms of rasta disease in Ghana (TASVd and PSTVd) or sap prepared from an infected tomato plant (CLVd). D, Close-up of tomato leaves of a plant infected with PSTVd showing epinasty and vein necrosis.
A BLASTn search indicated that the sequence of the PSTVd isolates from Ghana was identical to that of a tomato isolate from the United Kingdom (AJ583449), 99\% identical to those of a pepper isolate from New Zealand (AY532801) and a tomato isolate from the Netherlands (KF493732), and 94\% identical to those of PSTVd isolates from Europe (Italy, HQ452413 and the Netherlands, KY936876), the United States (HM753555), and Russia (EU879913). Thus, the PSTVd isolates from two tomato-growing regions of Ghana were genetically identical, and had high levels of nucleotide sequence identity with isolates from other geographic regions.

The complete nucleotide sequences of two TASVd isolates from Akumadan (OB1 and OB3) and two isolates from Tuobodom (OB4 and OB18) were determined from PCR-amplified cDNA fragments. These isolates also came from different infected tomato seedlings. The genomes of OB 1 from Akumadan and OB 18 from Tuobodom are $360 \mathrm{nt}$, and the sequences are 99\% identical (2 nt differences), whereas the genomes of OB3 from Akumadan and OB4 from Tuobodom are $364 \mathrm{nt}$, and the sequences are $94 \%$ identical (21 nt differences). Because of the genetic diversity among these TASVd isolates from Ghana, the sequences of all four isolates were deposited in GenBank (MG132055, MG132056, MG132057, and MG132058). A BLASTn search indicated that the sequences of the TASVd isolates from Ghana were 96 to $98 \%$ identical to that of a tomato isolate from the United States (K00818) and 95 to $96 \%$ identical to those of the two tomato isolates from Senegal (EF051631 and EF551346). Lower levels of identity were obtained for other TASVd isolates. Thus, a higher level of genetic diversity was detected for TASVd isolates from Ghana, and these isolates were closely related to some from other geographic regions.

To further investigate the relationships among the viroid isolates from Ghana and tomato-infecting pospiviroid isolates and species from other geographic regions, an alignment was generated with the complete genome sequences of 53 viroid isolates. This included 20 TASVd, 14 PSTVd, and 11 CLVd isolates, as well as isolates of 7 other tomato-infecting viroid species. The sequence of Dahlia latent viroid, a recently characterized pospiviroid species that does not infect tomato (Verhoeven et al. 2013), was used as the outgroup. This alignment was used to conduct a phylogenetic analysis and to generate a phylogenetic tree (Fig. 3). The PSTVd isolates from Ghana (OB21, OB25, OB27, and OB36) were placed in a clade with tomato isolates from Turkey and Germany, whereas the other tomato isolates from diverse geographic regions (New Zealand, the United States, and various countries of Europe) were placed into other clades (Fig. 3). The TASVd isolates OB1, OB3, and OB18 from Ghana were placed in a clade with a tomato isolate from the United States, whereas the OB4 isolate was placed in another clade with the two tomato isolates from Senegal (Fig. 3). The other TASVd isolates, mostly from countries of Europe, were placed in another larger clade, with the exception of an isolate from Germany. These results reflected the greater level of genetic diversity detected among isolates of TASVd from Ghana. Thus, isolates of both viroids from Ghana are closely related to isolates from other geographic regions, consistent with long-distance dissemination in association with seed.

Host range of PSTVd and TASVd isolates from Ghana. This experiment was performed by mechanical (rub) inoculation of a series of plant species, which were selected based on being common indicator plants or vegetable crops that could play a role in rasta disease in Ghana. Sap was prepared from symptomatic leaves collected from 4-week-old tomato plants (Early Pak 7) infected with CLVd, PSTVd, or TASVd, whereas the negative control consisted of plants inoculated with buffer alone. The isolate of CLVd from Mali (Mali OB1 2011) was included as a positive control because it causes rasta-like symptoms in tomato and the host range was previously investigated (Batuman et al. 2013). PSTVd isolates from Akumadan (OB25) and Tuobodom (OB36) and TASVd isolates from Akumadan (OB1) and Tuobodom (OB4) were used in three independent inoculations, each with three plants of each species inoculated with each viroid or buffer alone (nine plants inoculated/treatment).

By 7 to 10 dpi, tomato plants (Early Pak 7) inoculated with each of these viroids were stunted and leaves showed epinasty, crumpling, 
and chlorosis. Necrosis of leaf veins, petioles, and stems appeared in these plants by 14 to $20 \mathrm{dpi}$ and, by $60 \mathrm{dpi}$, these plants had produced few or no fruit (Fig. 2A to D). Moreover, the fruit that were produced were small and had relatively few seed, many of which were small and discolored (Fig. 4A to C). The symptoms induced in Early Pak 7 by all isolates of these three viroids were indistinguishable, and were similar to those associated with rasta disease. In contrast, tomato plants of cultivar Glamour inoculated with these viroid isolates were symptomless or developed very mild symptoms, including slight stunting and sporadic small necrotic lesions in leaf veins and stems, by 14 to 20 dpi (Table 2). By 30 and 180 dpi, symptoms in Glamour plants remained absent or mild. These viroid-infected Glamour plants produced more fruit than those of infected Early Pak 7. When selected viroid-inoculated tomato plants of both cultivars were tested for infection by RT-PCR with viroid-specific primer pairs, all were positive for the inoculated viroid (i.e., CLVd, PSTVd, or TASVd). Furthermore, there were no obvious differences in viroid titers between plants of Early Pak 7 with severe symptoms or those of Glamour with mild symptoms based upon semiquantitative RT-PCR results (data not shown). These results revealed that these three viroids induce similar and strikingly different symptoms in these two tomato cultivars, and that viroid titers may not be correlated with symptom severity.

With the exception of Early Pak 7 tomato, disease symptoms were not observed in any of the other plant species inoculated with isolates of these viroids (Table 2). These plants remained symptomless over the course of each inoculation experiment (180 dpi), and were indistinguishable from mock-inoculated controls. However, when RNA extracts of these plants were tested by RT-PCR with viroidspecific primer pairs, viroid infection was detected in some of the

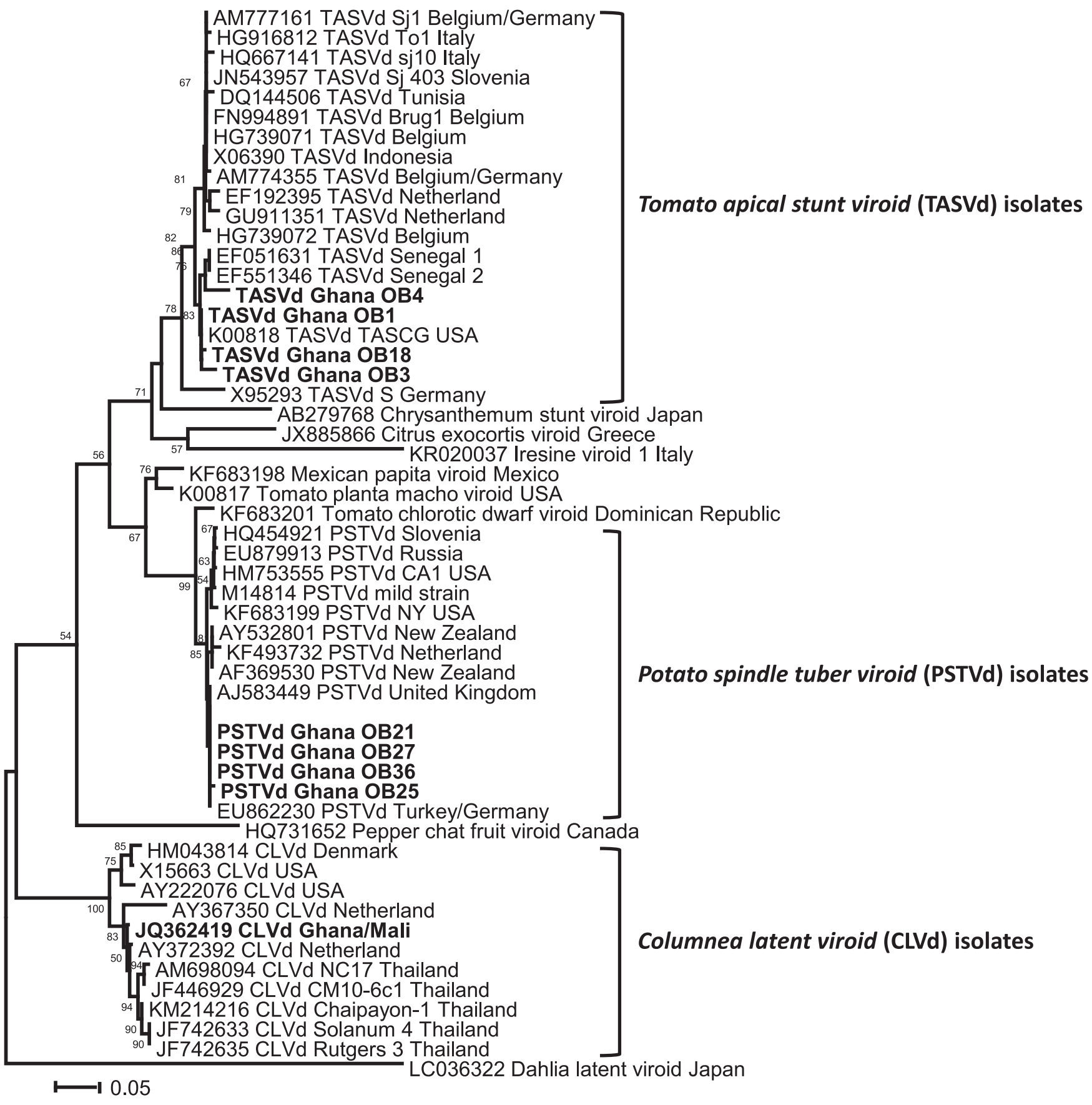

Fig. 3. Phylogenetic tree showing the relationship of Potato spindle tuber viroid (PSTVd) and Tomato apical stunt viroid (TASVd) isolates from Ghana with isolates of those viroids from other geographic regions and with other pospiviroid species. The phylogenetic tree was generated based on an alignment of the complete genome sequences of 53 viroid isolates, and the neighbor-joining method with 1,000 bootstrap values. 
symptomless solanaceous species by 14 dpi. Symptomless infections were detected for PSTVd and TASVd isolates in N. benthamiana, N. glutinosa, N. tabacum 'Turkish', and pepper (Table 2). The PSTVd isolates also caused symptomless infections in D. stramonium and N. tabacum 'Glurk' plants. CLVd induced symptomless infections in $N$. benthamiana, $N$. tabacum 'Turkish', and pepper, in agreement with previous results (Batuman et al. 2013). No symptoms were observed nor were symptomless infections detected by RT-PCR for any of these viroids in any of the inoculated Chenopodium quinoa, C. amaranticolor, common bean (Othello and Topcrop), pumpkin (Small Sugar), and cucumber (Emparator and Poinsett 76). These results revealed a very similar and limited host range for all three viroid species in terms of hosts that developed symptoms, even between two cultivars of tomato. All three viroids had a wider host range when symptomless hosts were included (Table 2), with PSTVd having the widest host range, followed by TASVd and CLVd.
Detection of PSTVd and TASVd isolates from Ghana in tomato leaf, fruit, seed, and seedlings. Here, two experiments-(i) detection of these viroids in tomato organs and (ii) detection of viroids in seedlings emerging from seed from viroid-infected plants-were conducted with the same set of inoculated plants. In each of three independent inoculations, eight tomato seedlings (Early Pak 7) were mechanically (rub) inoculated with sap prepared from PSTVd- and TASVd-infected tomato plants. The negative control was eight plants mock inoculated with inoculation buffer only. By 7 to $10 \mathrm{dpi}$, all of the viroid-inoculated plants in the three inoculations developed leaf epinasty and crumpling symptoms, whereas mock-inoculated plants did not develop symptoms. At 90 dpi, when samples were collected to detect viroids in plant organs, viroidinfected plants showed symptoms of rasta disease, whereas mockinoculated plants remained without symptoms. In RT-PCR tests with RNA extracted from leaves, fruit, and seed of PSTVd- and TASVdinfected plants, the expected-size DNA fragment (approximately $360 \mathrm{nt}$ )
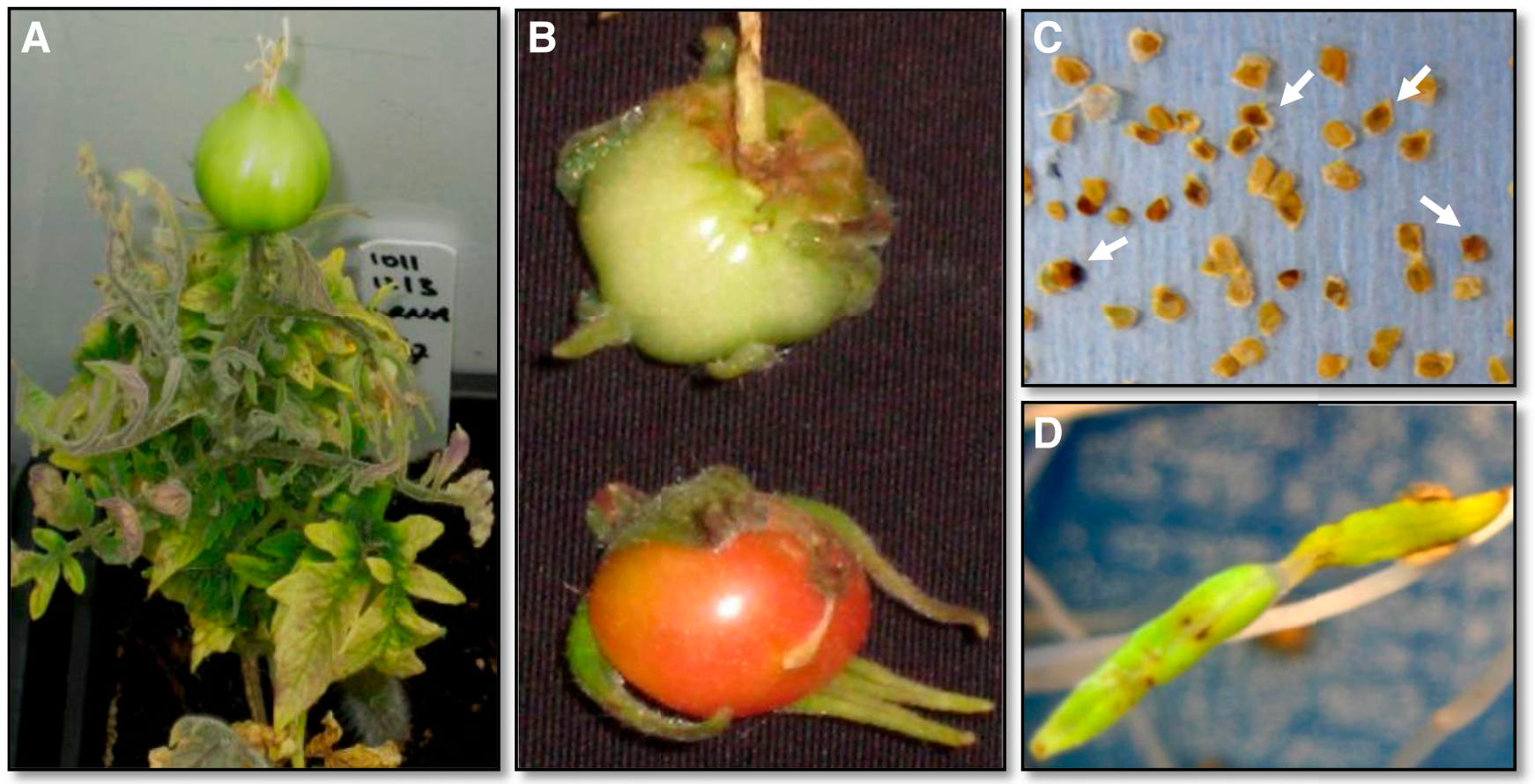

E

TASVd FOB and ROB Primers

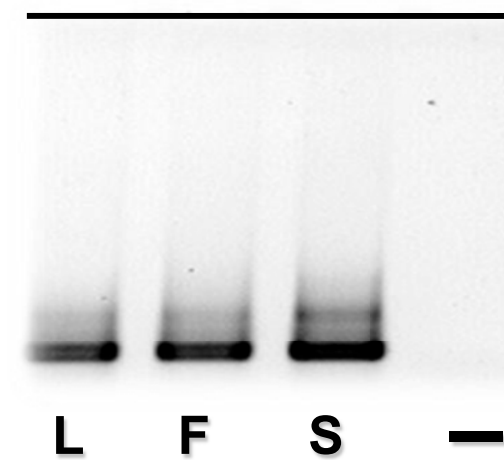

\section{PSTVd FOB1 and ROB1 Primers}

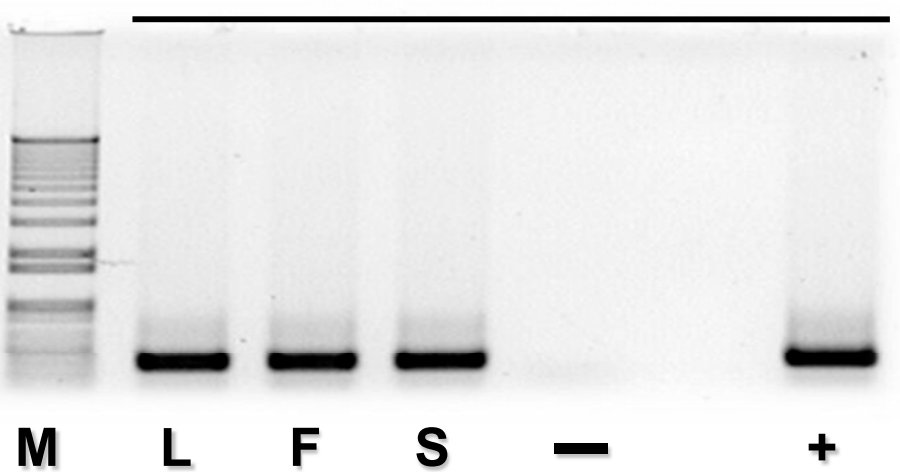

Fig. 4. Detection of Potato spindle tuber viroid (PSTVd) and Tomato apical stunt viroid (TASVd) isolates from Ghana in tomato leaf, fruit, and seed from infected plants. A and B, Single fruit produced by a viroid-infected plant with severe rasta symptoms, and small-sized fruit from such plants that produce small numbers of seed. $\mathbf{C}$, Small-sized and discolored seed (shown by arrows) extracted from fruit collected from viroid-infected plants. D, Necrotic lesions in cotyledonary leaves of a tomato seedling from a seed extracted from fruit from a TASVd-infected plant. E, Detection of PSTVd and TASVd in leaf $(\mathrm{L})$ and fruit (F) tissues and seed (S) collected from tomato plants infected with these viroids by reverse-transcription polymerase chain reaction (RT-PCR) with specific primer pairs. The expected-size DNA fragments (approximately 360 bp each) were amplified from leaf and fruit tissues and seed of viroid-infected plants but not from equivalent organs of mock-inoculated plants. $\mathrm{M}=1$-kb DNA ladder, $-=$ PCR without cDNA (negative control), and $+=$ RT-PCR with total RNA extracts from PSTVd- and TASVd-infected tomato leaves (positive controls). 
was amplified from all organs of all viroid-infected plants (Fig. 4E). Moreover, the titer of viroid RNA detected in all three organs and for both viroids was similar (Fig. 4E). Viroid RNA was not detected from equivalent organs of mock-inoculated tomato plants. These results indicate that both viroids extensively spread and infected tomato plants of this highly susceptible cultivar, including fruit and seed.

It is well established that viroids, including PSTVd and TASVd, can be seed transmitted in tomato (Batuman and Gilbertson 2013; Matushita and Tsuda 2016; Singh 1970). Therefore, in this experiment, we tested whether isolates of PSTVd and TASVd from Ghana were seed transmitted by germinating seed collected from the PSTVd- and TASVd-infected tomato plants described above, and testing for viroid infection in hypocotyls and cotyledonary leaves by RT-PCR with specific primers. The negative controls were seedlings derived from seed extracted from fruit collected from uninfected plants. In these experiments, a small number of seedlings $(<1 \%)$ that developed from seed collected from PSTVd- or TASVd-infected plants had necrotic lesions in hypocotyls and cotyledonary leaves (Fig. 4D). Moreover, the seedlings with these necrotic lesions were positive for PSTVd or TASVd in RT-PCR tests, indicating that these lesions were associated with viroid infection. Furthermore, RT-PCR tests with specific primers revealed relatively low rates of viroid infection $(<1 \%)$ of the randomly collected hypocotyls and cotyledonary leaves of the seedlings from seed extracted from PSTVd- and TASVd-infected fruit. Based on the single experiment conducted with approximately 150 tomato seeds for the two isolates each of PSTVd and TASVd, the rate of seed transmission (based on the total number of hypocotyls and cotyledonary leaves in which the viroid RNA was detected by RT-PCR) was $1 \%$ (ranging from 0 to $2 \%$ ). Hypocotyls and cotyledons of seedlings from seed of fruit from uninfected plants did not show these necrotic lesions, nor was viroid RNA detected from hypocotyls and cotyledonary leaves of these seedlings (data not shown). These results demonstrated that these PSTVd and TASVd isolates may be seed transmitted in tomato, and that our OB primers could be used to detect these viruses directly in contaminated seed by RT-PCR.

\section{Discussion}

In the present study, we established that rasta disease of tomato in Ghana is caused by the viroids PSTVd and TASVd. A viroid etiology for this disease is fully consistent with (i) failure to detect common

Table 2. Partial host range and symptomatology of three pospiviroids associated with rasta disease symptoms in tomato in Ghana and Mali

\begin{tabular}{lccc}
\hline & \multicolumn{3}{c}{ Detected/symptoms } \\
\cline { 2 - 4 } Plant species & TASVd & PSTVd & CLVd \\
\hline Nicotiana benthamiana & $+/-$ & $+/-$ & $+/-$ \\
$N$. tabacum 'Havana' & $+/-$ & $+/-$ & $-/-$ \\
$N$. tabacum 'Turkish' & $+/-$ & $+/-$ & $+/-$ \\
$N$. tabacum 'Glurk' & $-/-$ & $+/-$ & $-/-$ \\
$N$. glutinosa & $+/-$ & $+/-$ & $-/-$ \\
Chenopodium amaranticolor & $-/-$ & $-/-$ & $-/-$ \\
C. quinoa & $-/-$ & $-/-$ & $-/-$ \\
Datura stramonium & $-/-$ & $+/-$ & $-/-$ \\
Cucurbita pepo 'Small Sugar' & $-/-$ & $-/-$ & $-/-$ \\
Capsicum annuum 'Yolo Wonder' & $+/-$ & $+/-$ & $+/-$ \\
Solanum lycopersicum 'Glamour' & $+/-$ & $+/-$ & $+/-$ \\
S. lycopersicum 'Early Pak 7' & $+/+$ & $+/+$ & $+/+$ \\
Cucumis sativus 'Emparator and Poinsett 76' & $-/-$ & $-/-$ & $-/-$ \\
Phaseolus vulgaris 'Topcrop' & $-/-$ & $-/-$ & $-/-$ \\
P. vulgaris 'Othello' & $-/-$ & NT & NT \\
\hline
\end{tabular}

${ }^{a}$ Detected by reverse-transcription polymerase chain reaction (RT-PCR)/development of disease symptoms. Based on results of three inoculation experiments with three plants per inoculation (nine plants per viroid per plant species). TASVd = Tomato apical stunt viroid, PSTVd = Potato spindle tuber viroid, and CLVd $=$ Columnea latent viroid. For viroid detection: $+=$ detection of the expected-size DNA fragment in RT-PCR tests with viroid-specific primer pairs, $-=$ the expected-size fragment was not detected, and NT $=$ not tested. For observation of symptoms: $+=$ development of obvious disease symptoms and $-=$ no obvious symptoms were observed. tomato-infecting viruses in plants with rasta symptoms, (ii) the type of disease symptoms (i.e., severe stunting; epinasty, crumpling, and chlorosis of leaves; and necrosis of leaf veins, petioles, and stems), (iii) the infectious nature of RNA extracts from symptomatic leaf samples, and (iv) the development of rasta-like symptoms in tomato plants (Early Pak 7) mechanically inoculated with sap prepared from leaves of PSTVd- or TASVd-infected tomato plants. Although these viroids have been previously reported to infect tomato in other countries in Africa (Candresse et al. 2007; OEPP/EPPO 2014; Walter 1981, 1987), this is the first report from Ghana (note that an abstract of this work has been published by Batuman et al. [2013]). Taken together with our previous report that CLVd induces rasta-like symptoms in tomato in Mali (Batuman and Gilbertson 2013) and the subsequent detection of CLVd in a rasta sample from Ghana (data not shown) (Fig. 3), our results establish that rasta disease can be caused by three viroids: CLVd, PSTVd, and TASVd. Furthermore, these three viroids cause similar rasta-like symptoms in tomato (at least in Early Pak 7), which necessitates the use of molecularbased tests to identify the precise viroids causing the disease in a given geographical region. Finally, the observation of rasta-like symptoms in commercial tomato fields in Benin, Burkina Faso, and Senegal during other disease surveys indicates that this disease is widely distributed in West Africa.

Diagnosis and identification of viroid diseases is challenging because of (i) the wide range of symptoms induced, including symptomless infections, and (ii) the unreliability of molecular detection tests (e.g., RT-PCR with degenerate primers). In the present study, viroid infection was not detected in 3 of 13 samples collected from plants with rasta-like symptoms in Ghana, indicating that symptoms alone are not sufficient for disease diagnosis and that other factors can induce rasta-like symptoms, especially early in disease development (Fig. 1A and B). Thus, additional diagnostic tests are necessary to confirm viroid infection. However, RT-PCR tests can also be unreliable for viroid detection and identification due to differences in primer or viroid sequences, primer annealing conditions, RNA extraction methods, and viroid titer (Cohen et al. 2006; Gucek et al. 2017). Indeed, our initial attempts to detect viroids in RNA extracts prepared from rasta disease samples applied to FTA cards in RT-PCR tests with degenerate viroid primer pairs were inconclusive due to nonspecific amplification of presumably host-derived nucleic acids. This was not due to the inability to extract viroid RNA from FTA cards or problems with the cDNA or RT-PCR procedures, because viroid RNA was successfully amplified from RNA extracts prepared from subsequent FTA cards with samples of CLVd-, PSTVd-, or TASVd-infected leaves by RT-PCR with viroid-specific primer pairs. It is more likely that this was due to low viroid titers in the field-collected rasta disease samples or primer annealing conditions used in the cDNA or RT-PCR tests.

The biological indicator (tomato seedlings of the highly susceptible Early Pak 7) allowed for the identification of infectious viroid RNA in extracts prepared from 10 of the 13 original samples applied to FTA cards. Moreover, this provided two key lines of evidence for the viroid etiology of this disease: (i) the infectious nature of RNA extracts prepared from the rasta samples applied to FTA cards and (ii) the development of rasta-like symptoms in tomato seedlings inoculated with these extracts. This biological indicator was subsequently used to increase and maintain the three viroid species used in this study. Additional and definitive evidence for the role of two viroids in rasta disease came from (i) the detection of PSTVd and TASVd in the leaves of these tomato seedlings with rasta symptoms by RT-PCR with newly designed primer pairs (PSTVd-FOB1/ ROB1, PSTVd-FOB2/ROB2, and TASVd-FOB/ROB) (Table 1) and (ii) the mechanical (sap) transmission of isolates of these viroids to tomato seedlings and subsequent development of rasta-like symptoms. These primer pairs should be useful in future studies of these viroids in West Africa and other geographic regions. Finally, our results also highlight the challenges associated with viroid detection and the need to use multiple approaches to confirm viroid infection.

The abutting OB primer pairs (Table 1) mediated the amplification and sequencing of the complete genomes of PSTVd and TASVd 
isolates associated with rasta disease of tomato in Ghana. The PSTVd and TASVd isolates from Ghana had high levels of identity (94 to 100\%) with previously characterized isolates from other geographic regions, and were placed in phylogenetic clades with some of these isolates. This is suggestive of long-distance dissemination, most likely in association with tomato seed. Isolates of PSTVd and TASVd from Ghana differed in their genetic diversity. The four PSTVd isolates from multiple locations in two tomato-growing regions of Ghana had identical sequences, which may indicate a single introduction event followed by local spread with seed or transplants. In contrast, the TASVd isolates were genetically diverse, in terms of genome size and sequence, and comprised at least two haplotypes. This suggests multiple introduction events. An isolate of one haplotype was closely related to the two isolates from Senegal. This may reflect geographic proximity and local spread following an initial introduction event. The close relationship of the other TASVd isolates from Ghana (including both haplotypes) with an isolate from the United States also likely reflects long-distance dissemination (Fig. 3).

The results of the host range experiment confirmed that PSTVd and TASVd isolates from Ghana cause rasta disease in the highly susceptible tomato Early Pak 7, and provided additional support to the hypothesis that each of these viroids can cause this disease in Ghana. The induction of rasta symptoms in this cultivar by the isolate of CLVd from Mali is consistent with a previous report indicating that this viroid also causes rasta-like disease symptoms (Fig. 2C) (Batuman and Gilbertson 2013). These three viroids induced mild or no symptoms in Glamour tomato, revealing differential virulence in cultivars of tomato. This is in agreement with previous reports that PSTVd isolates differentially infected cultivars of tomato and potato (Hammond and Zhao 2000; Owens and Hammond 2009; Sano et al. 1992). The findings that (i) few plant species tested developed symptoms following inoculation with these viroids (e.g., only a single tomato cultivar in the present study) and (ii) symptomless infections were detected in other species (various solanaceous species in the present study) are in agreement with previous studies of the host range of PSTVd and TASVd and further show the complexity of the viroid-host interaction (Diener 2003; Ding 2009; Flores et al. 2005, 2014; Hull 2013; Matsushita and Tsuda 2015; Navarro et al. 2012; Tabler and Tsagris 2004). Furthermore, although the host range studies of PSTVd and TASVd conducted by Matsushita and Tsuda (2015) and in the present study are difficult to compare directly because of focusing on plant species commonly imported into Japan versus indicator plants and agricultural plants, respectively, both studies revealed few species that developed symptoms but a relatively broad host range when symptomless hosts were included. Differential virulence in solanaceous species also revealed biological differences among these viroid species. Here, PSTVd infected the most species and CLVd the least (Table 2). Finally, the results of the host range also revealed that symptomless hosts could play a role in the epidemiology of rasta disease by serving as inoculum sources or a means of long-distance dissemination.

The infection of tomato plants and seed by isolates of PSTVd and TASVd from Ghana was investigated by employing RT-PCR tests with specific primer pairs. By $90 \mathrm{dpi}$, high titers of PSTVd and TASVd RNA were consistently detected in leaf and fruit tissues as well as seed of infected tomato plants (Early Pak 7), indicating extensive systemic spread throughout plants of this highly susceptible cultivar by both viroids. This was not unexpected given the severe rasta-like symptoms that were present in these plants. What was perhaps less expected was the detection of similar high viroid RNA titers in PSTVd- and TASVd-infected Glamour plants, which had mild or no symptoms. This revealed that there was no correlation between symptom severity and viral titer, at least for these two tomato cultivars. This raises intriguing questions regarding the underlying basis of symptom expression (i.e., how plants of Glamour can sustain such high viroid titers without developing severe symptoms). On a practical level, the planting of tomato cultivars that develop symptomless infections may allow for higher yields than those that develop severe symptoms and, in the present study, viroid-infected Glamour plants produced substantially more fruit than did infected Early Pak 7 plants. However, such symptomless plants would also serve as potential inoculum sources for infection of highly susceptible cultivars that develop severe symptoms of rasta disease.

The consistent detection of PSTVd and TASVd from RNA isolated from tomato seed extracted from fruit collected from viroidinfected plants revealed a strong association with seed but did not establish the location of the viroid RNA (i.e., whether it was on the inside or outside of seed). The detection of PSTVd and TASVd RNA in hypocotyls and cotyledonary leaves of seedlings that developed from seed extracted from fruit of viroid-infected plants, but not from those from seed of fruit from uninfected plants, demonstrated the potential for these viroids to be seed transmitted. Furthermore, the low rate of viroid infection of these seedlings $(1 \%)$ is in agreement with rates previously reported for these viroids in tomato seed (Matsushita and Tsuda 2016), suggesting that most of the viroid RNA was located on the outside of seed (e.g., on the seed coat rather than in the embryo or cotyledons). Finally, because most of the viroid-infected seedlings had necrotic lesions in hypocotyls and cotyledonary leaves (Fig. 4D), it is possible that such seedlings may not give rise to viable tomato plants. Thus, additional experiments need to be conducted to definitively establish seed transmission rates. However, these results are consistent with previous reports of the association and transmission of PSTVd and TASVd with tomato seed (Antignus et al. 2007; Goss 1926; Matsushita and Tsuda 2014, 2016). Together, these results suggest that tomato seed are a potential inoculum source for isolates of these viroids in commercial tomato fields in Ghana, particularly for farmers that extract seed from fruit collected from fields having viroid-infected plants. Moreover, this also raises the possibility that these viroids were inadvertently introduced into West African countries in contaminated or infected tomato seed produced in other countries. This hypothesis gains support from the high levels of sequence identity among the isolates of PSTVd and TASVd from Ghana and those from other regions of the world, including Asia, Europe, and North America.

In conclusion, we have established that the rasta disease of tomato in Ghana, a disease of unknown etiology, is caused by PSTVd and TASVd. Together with a previous report that CLVd induces a similar disease of tomato in Mali (Batuman and Gilbertson 2013) and our subsequent detection of CLVd in a tomato sample with rasta symptoms from Ghana, our results indicate that rasta disease is caused by three different pospiviroid species (CLVd, PSTVd, and TASVd). Although the overall incidence of rasta disease in the surveyed fields was relatively low (4\%), fields with higher incidences and reduced yield and quality have been observed in other surveys, suggesting the potential for the disease to become economically important. Effective management of these viroids will require planting viroidfree seed, either purchased from a commercial source or locally collected from uninfected plants; roguing infected plants early in the growing season; and possibly planting cultivars that develop mild or no symptoms. Future efforts should be made to determine the presence and relative importance of viroid diseases in tomato in other countries of West Africa.

\section{Literature Cited}

Adkar-Purushothama, C. R., Brosseau, C., Giguere, T., Sano, T., Moffett, P., and Perreault, J. P. 2015. Small RNA derived from the virulence modulating region of the Potato spindle tuber viroid silences callose synthase genes of tomato plants. Plant Cell 27:2178-2194.

Altschul, S. F., Gish, W., Miller, W., Myers, E. W., and Lipman, D. J. 1990. Basic local alignment search tool. J. Mol. Biol. 215:403-410.

Antignus, Y., Lachman, O., and Pearlsman, M. 2007. Spread of Tomato apical stunt viroid (TASVd) in greenhouse tomato crops is associated with seed transmission and bumble bee activity. Plant Dis. 91:47-50.

Antignus, Y., Lachman, O., Pearlsman, M., Gofman, R., and Bar-Joseph, M. 2002. A new disease of greenhouse tomatoes in Israel caused by a distinct strain of Tomato apical stunt viroid (TASVd). Phytoparasitica 30: 502-510.

Bar-Joseph, M. 2003. Natural history of viroids. Pages 246-250 in: Viroids A. Hadidi, ed. CSIRO Publishing, Collingwood, Australia.

Batuman, O., and Gilbertson, R. L. 2013. First report of Columnea latent viroid (CLVd) in tomato in Mali. Plant Dis. 97:692. 
Batuman, O., Osei, M. K., Mochiah, M. B., Lamptey, J. N., Miller, S. and Gilbertson, R. L. 2013. The first report of Tomato apical stunt viroid (TASVd) and Potato spindle tuber viroid (PSTVd) in tomatoes in Ghana. (Abstr.) Phytopathology 103:S2.12.

Bostan, H., Nie, X., and Singh, R. P. 2004. An RT-PCR primer pair for the detection of pospiviroid and its application in surveying ornamental plants for viroids. J. Virol. Methods 116:189-193.

Branch, A. D., and Robertson, H. D. 1984. A replication cycle for viroids and other small infectious RNAs. Science 223:450-455.

Candresse, T., Marais, A., Ollivier, F., Verdin, E., and Blancard, D. 2007. First report of the presence of Tomato apical stunt viroid on tomato in Senegal. Plant Dis. 91:330.

Candresse, T., Marais, A., Tassus, X., Suhard, P., Renaudin, I., Leguay, A., Poliakoff, F., and Blancard, D. 2010. First report of Tomato chlorotic dwarf viroid in tomato in France. Plant Dis. 94:633.

Chen, L.-F., Rojas, M., Kon, T., Gamby, K., Xoconostle-Cazares, B., and Gilbertson, R. L. 2009. A severe symptom phenotype in tomato in Mali is caused by a reassortant between a novel recombinant begomovirus (Tomato yellow leaf curl Mali virus) and a betasatellite. Mol. Plant Pathol. 10:415-430.

Cohen, O., Batuman, O., Moskowits, Y., Rozov, A., Gootwine, E., Mawassi, M., and Bar-Joseph, M. 2005. Goat horns: Platforms for viroid transmission to fruit trees? Phytoparasitica 33:141-148.

Cohen, O., Batuman, O., Stanbekova, G., Sano, T., Mawassi, M., and Bar-Joseph, M. 2006. Construction of a multiprobe for the simultaneous detection of viroids infecting citrus trees. Virus Genes 33:287-292.

Daros, J. A., Marcos, J. F., Hernandez, C., and Flores, R. 1994. Replication of avocado sunblotch viroid: Evidence for a symmetrical pathway with two rolling circles and hammerhead ribozyme processing. Proc. Natl. Acad. Sci. USA 91:12813-12817

De Bokx, J. A., and Piron, P. G. M. 1981. Transmission of Potato spindle tuber viroid by aphids. Neth. J. Plant Pathol. 87:31-34.

De la Peña, M., and Flores, R. 2002. Chrysanthemum chlorotic mottle viroid RNA: Dissection of the pathogenicity determinant and comparative fitness of symptomatic and non-symptomatic variants. J. Mol. Biol. 321:411-421.

Di Serio, F., Flores, R., Verhoeven, J. T., Li, S. F., Pallas, V., Randles, J. W., Sano, T., Vidalakis, G., and Owens, R. A. 2014. Current status of viroid taxonomy. Arch. Virol. 159:3467-3478.

Diener, T. O. 1971. Potato spindle tuber "virus". IV. A replicating, low molecular weight RNA. Virology 45:411-428.

Diener, T. O. 1979. Viroid discovery. Science 206:886

Diener, T. O. 2003. Discovering viroids-a personal perspective. Nat. Rev. Microbiol. 1:75-80.

Ding, B. 2009. The biology of viroid-host interactions. Annu. Rev. Phytopathol. 47:105-131.

Fadda, Z., Daros, J. A., Fagoaga, C., Flores, R., and Duran-Vila, N. 2003. Eggplant latent viroid, the candidate type species for a new genus within the family Avsunviroidae (hammerhead viroids). J. Virol. 77:6528-6532.

Flores, R., Daros, J. A., and Hernandez, C. 2000. Avsunviroidae family: Viroids containing hammerhead ribozymes. Adv. Virus Res. 55:271-323.

Flores, R., Gago-Zachert, S., Serra, P., Sanjuan, R., and Elena, S. F. 2014. Viroids: Survivors from the RNA world? Annu. Rev. Microbiol. 68:395-414.

Flores, R., Gas, M. E., Molina-Serrano, D., Nohales, M. A., Carbonell, A., Gago, S., De la Peña, M., and Daros, J. A. 2009. Viroid replication: Rolling-circles, enzymes and ribozymes. Viruses 1:317-334.

Flores, R., Hernandez, C., Martinez de Alba, A. E., Daros, J. A., and Di Serio, F. 2005. Viroids and viroid-host interactions. Annu. Rev. Phytopathol. 43: 117-139.

Galindo A, J., Smith, D. R., and Diener, T. O. 1982. Etiology of planta macho, a viroid disease of tomato. Phytopathology 72:49-54.

Gast, F. U., Kempe, D., Spieker, R. L., and Sanger, H. L. 1996. Secondary structure probing of Potato spindle tuber viroid (PSTVd) and sequence comparison with other small pathogenic RNA replicons provides evidence for central non-canonical base-pairs, large A-rich loops, and a terminal branch. J. Mol. Biol. 262:652-670.

Goss, R. W. 1926. Transmission of potato spindle tuber by cutting knives and seed piece contact. Phytopathology 16:299-303.

Gucek, T., Trdan, S., Jakse, J., Javornik, B., Matousek, J., and Radisek, S. 2017. Diagnostic techniques for viroids. Plant Pathol. 66:339-358.

Hadidi, A., Giunchedi, L., Shamloul, A., Poggi-Pollini, C., and Amer, M. 1997. Occurrence of Peach latent mosaic viroid in stone fruits and its transmission with contaminated blades. Plant Dis. 81:154-158.

Hailstones, D., Tesoriero, L., Terras, M., and Dephoff, C. 2003. Detection and eradication of Potato spindle tuber viroid in tomatoes in commercial production in New South Wales, Australia. Australas. Plant Pathol. 32: 317-318.

Hammond, R. W., and Zhao, Y. 2000. Characterization of a tomato protein kinase gene induced by infection by Potato spindle tuber viroid. Mol. Plant-Microbe Interact. 13:903-910.

Hull, R. 2013. Agents resembling or altering virus diseases. Pages 199-243 in: Plant Virology, fifth ed. Academic Press, Cambridge, MA.

Kryczyński, S., Paduch-Cichal, E., and Skrzeczkowski, L. 1988. Transmission of three viroids through seed and pollen of tomato plants. J. Phytopathol. 121: $51-57$
Lamptey, J. N. L., Osei, M. K., Mochiah, M. B., Osei, K., Berchie, J. N., BolfreyArku, G., and Gilbertson, R. L. 2013. Serological detection of Tobacco mosaic virus and Cucumber mosaic virus infecting tomato (Solanum lycopersicum) using a lateral flow immunoassay technique. J. Agric. Stud. 1:102-113.

Lebas, B. S. M., Clover, G. R. G., Ochoa-Corona, F. M., Elliott, D. R., Tang, Z., and Alexander, B. J. R. 2005. Distribution of Potato spindle tuber viroid in New Zealand glasshouse crops of capsicum and tomato. Australas. Plant Pathol. 34 129-133.

Leke, W. N., Mignouna, D. B., Brown, J. K., and Kvarnheden, A. 2015. Begomovirus disease complex: Emerging threat to vegetable production systems of West and Central Africa. Agric. Food Secur. 4:1.

Ling, K.-S., and Bledsoe, M. 2009. First report of Mexican papita viroid infecting greenhouse tomato in Canada. Plant Dis. 93:839.

Ling, K. S., Li, R., Groth-Helms, D., and Assis-Filho, F. M. 2014. First report of Potato spindle tuber viroid naturally infecting field tomatoes in the Dominican Republic. Plant Dis. 98:701.

Ling, K. S., Li, R., Panthee, D. R., and Gardner, R. G. 2013. First report of Potato spindle tuber viroid naturally infecting greenhouse tomatoes in North Carolina. Plant Dis. 97:148.

Ling, K. S., and Sfetcu, D. 2010. First report of natural infection of greenhouse tomatoes by Potato spindle tuber viroid in the United States. Plant Dis. 94:1376.

Ling, K. S., Verhoeven, J. T. J., Singh, R. P., and Brown, J. K. 2009. First report of Tomato chlorotic dwarf viroid in greenhouse tomatoes in Arizona. Plant Dis. 93:1075.

Ling, K. S., and Zhang, W. 2009. First report of a natural infection by Mexican papita viroid and Tomato chlorotic dwarf viroid on greenhouse tomatoes in Mexico. Plant Dis. 93:1216.

Mater, Y. J., Chen, L.-F., Osei, M. K., and Gilbertson, R. L. 2015. Genetic analysis of begomoviruses and betasatellites associated with tomato leaf curl disease in Ghana. (Abstr.) Phytopathology 105:S4.90.

Matsushita, Y., Kanda, A., Usugi, T., and Tsuda, S. 2008. First report of a Tomato chlorotic dwarf viroid disease on tomato plants in Japan. J. Gen. Plant Pathol. 74:182-184.

Matsushita, Y., and Tsuda, S. 2014. Distribution of Potato spindle tuber viroid in reproductive organs of petunia during its developmental stages. Phytopathology 104:964-969.

Matsushita, Y., and Tsuda, S. 2015. Host ranges of Potato spindle tuber viroid, Tomato chlorotic dwarf viroid, Tomato apical stunt viroid, and Columnea latent viroid in horticultural plants. Eur. J. Plant Pathol. 141:193-197.

Matsushita, Y., and Tsuda, S. 2016. Seed transmission of Potato spindle tuber viroid, Tomato chlorotic dwarf viroid, Tomato apical stunt viroid, and Columnea latent viroid in horticultural plants. Eur. J. Plant Pathol. 145: 1007-1011.

Matsuura, S., Matsushita, Y., Kozuka, R., Shimizu, S., and Tsuda, S. 2010 Transmission of Tomato chlorotic dwarf viroid by bumblebees (Bombus ignitus) in tomato plants. Eur. J. Plant Pathol. 126:111-115.

Mink, G. 1993. Pollen and seed-transmitted viruses and viroids. Annu. Rev. Phytopathol. 31:375-402.

Mishra, M. D., Hammond, R. W., Owens, R. A., Smith, D. R., and Diener, T. O. 1991. Indian bunchy top disease of tomato plants is caused by a distinct strain of Citrus exocortis viroid. J. Gen. Virol. 72:1781-1785.

Murcia, N., Bernad, L., Duran-Vila, N., and Serra, P. 2011. Two nucleotide positions in the Citrus exocortis viroid RNA associated with symptom expression in Etrog citron but not in experimental herbaceous hosts. Mol. Plant Pathol. 12:203-208.

Navarro, B., Gisel, A., Rodio, M. E., Delgado, S., Flores, R., and Di Serio, F. 2012 Viroids: How to infect a host and cause disease without encoding proteins. Biochimie 94:1474-1480.

Navarro, B., Silletti, M. Trisciuzzi, V., and Di Serio, F. 2009. Identification and characterization of Potato spindle tuber viroid infecting tomato in Italy. J. Plant Pathol. 91:723-726.

Ndunguru, J., Taylor, N. J., Yadav, J., Aly, H., Legg, J. P., Aveling, T., Thompson, G., and Fauquet, C. M. 2005. Application of FTA technology for sampling, recovery and molecular characterization of viral pathogens and virus-derived transgenes from plant tissues. Virol. J. 2:45.

OEPP/EPPO. 2014. Data sheets on quarantine organisms. Potato spindle tuber viroid. https://gd.eppo.int/download/doc/214_datasheet_PSTVD0.pdf

Owens, R. A., and Hammond, R. W. 2009. Viroid pathogenicity: One process, many faces. Viruses 1:298-316.

Pallas, V., Martinez, G., and Gomez, G. 2012. The interaction between plan viroid-induced symptoms and RNA silencing. Methods Mol. Biol. 894: 323-343.

Parrella, G., and Numitone, G. 2014. First report of Tomato apical stunt viroid in tomato in Italy. Plant Dis. 98:1164.

Pearson, M. N., Clover, G. R. G., Guy, P. L., Fletcher, J. D., and Beever, R. E. 2006. A review of the plant virus, viroid and mollicute records for New Zealand. Australas. Plant Pathol. 35:217-252.

Perez, K., Froikin-Gordon, J. S., Abdourhamane, I., Levasseur, V., Alfari, A., Mensah, A., Bonsu, O., Habsatou, B., Assogba-Komlan, F., Mbaye, A., Noussourou, M., Otoidobiga, L. C., Ouedraogo, L., Kon, T., Rojas, M. R., Gamby, K. T., Shotkowski, F., Gilbertson, R. L., and Jahn, M. M. 2017. Connecting smallholder tomato producers to improved seed in West Africa Agric. Food Secur. 6:42. 
Reanwarakorn, K., Klinkong, S., and Porsoongnurn, J. 2011. First report of natural infection of Pepper chat fruit viroid in tomato plants in Thailand. New Dis. Rep. 24:6.

Saitou, N., and Nei, M. 1987. The neighbor-joining method: A new method for reconstructing phylogenetic trees. Mol. Biol. Evol. 4:406-425.

Sanger, H. L., Klotz, G., Riesner, D., Gross, H. J., and Kleinschmidt, A. K. 1976. Viroids are single-stranded covalently closed circular RNA molecules existing as highly base-paired rod-like structures. Proc. Natl. Acad. Sci. U.S.A. 73:3852-3856.

Sano, T., Candresse, T., Hammond, R. W., Diener, T. O., and Owens, R. A. 1992. Identification of multiple structural domains regulating viroid pathogenicity. Proc. Natl. Acad. Sci. U.S.A. 89:10104-10108.

Semancik, J., and Szychowski, J. 1992. Relationships among the viroids derived from grapevines. J. Gen. Virol. 73:1465-1469.

Singh, R. P. 1970. Seed transmission of potato spindle tuber virus in tomato and potato. Am. J. Potato Res. 47:225-227.

Singh, R. P., Lakshman, D. K., Boucher, A., and Tavantzis, S. M. 1992. A viroid from Nematanthus wettsteinii plants closely related to the Columnea latent viroid. J. Gen. Virol. 73:2769-2774.

Singh, R. P., Nie, X., and Singh, M. 1999. Tomato chlorotic dwarf viroid: An evolutionary link in the origin of pospiviroids. J. Gen. Virol. 80:2823-2828.

Singh, R. P., Singh, M., Boucher, A., and Owens, R. A. 1993. A mild strain of Potato spindle tuber viroid from China is similar to North American isolates. Can. J. Plant Pathol. 15:134-138.

Spieker, R. L. 1996. A viroid from Brunfelsia undulata closely related to the Columnea latent viroid. Arch. Virol. 141:1823-1832.

Szychowski, J., Goheen, A., and Semancik, J. 1988. Mechanical transmission and rootstock reservoirs as factors in the widespread distribution of viroids in grapevines. Am. J. Enol. Vitic. 39:213-216.

Tabler, M., and Tsagris, M. 2004. Viroids: Petite RNA pathogens with distinguished talents. Trends Plant Sci. 9:339-348.

Tamura, K., Stecher, G., Peterson, D., Filipski, A., and Kumar, S. 2013. MEGA6: Molecular Evolutionary Genetics Analysis version 6.0. Mol. Biol. Evol. 30: 2725-2729.

Thompson, J. D., Higgins, D. G., and Gibson, T. J. 1994. CLUSTAL W: Improving the sensitivity of progressive multiple sequence alignment through sequence weighting, position-specific gap penalties and weight matrix choice. Nucleic Acids Res. 22:4673-4680.
Van Bogaert, N., Olivier, T., Bragard, C., Maes, M., Smagghe, G., and De Jonghe, K. 2016. Assessment of pospiviroid transmission by Myzus persicae, Macrolophus pygmaeus and Bombus terrestris. Eur. J. Plant Pathol. 144 289-296.

Verhoeven, J. T. J., Arts, M. S. J., Owens, R. A., and Roenhorst, J. W. 1998 Natural infection of petunia by Chrysanthemum stunt viroid. Eur. J. Plant Pathol. 104:383-386.

Verhoeven, J. T. J., Jansen, C. C. C., Roenhorst, J. W., Flores, R., and de la Peña, M. 2009. Pepper chat fruit viroid: Biological and molecular properties of a proposed new species of the genus Pospiviroid. Virus Res. 144:209-214.

Verhoeven, J. T. J., Jansen, C. C. C., Willemen, T. M., Kox, L. F. F., Owens, R. A., and Roenhorst, J. W. 2004. Natural infections of tomato by Citrus exocortis viroid, Columnea latent viroid, Potato spindle tuber viroid and Tomato chlorotic dwarf viroid. Eur. J. Plant Pathol. 110:823-831.

Verhoeven, J. T. J., Meekes, E. T. M., Roenhorst, J. W., Flores, R., and Serra, P 2013. Dahlia latent viroid: A recombinant new species of the family Pospiviroidae posing intriguing questions about its origin and classification. J. Gen. Virol. 94:711-719.

Verhoeven, J. T. J., and Roenhorst, J. W. 2010. High stability of original predominant pospiviroid genotypes upon mechanical inoculation from ornamentals to potato and tomato. Arch. Virol. 155:269-274.

Verhoeven, J. T. J., Roenhorst, J. W., Hooftman, M., Meekes, E. T. M., Flores, R., and Serra, P. 2015. A pospiviroid from symptomless portulaca plants closely related to Iresine viroid 1 . Virus Res. 205:22-26.

Wallace, J., and Drake, R. 1962. High rate of seed transmission of Avocado sunblotch virus from symptomless trees and origin of such trees. Phytopathology 52:237-241.

Walter, B. 1981. A viroid on tomato in West-Africa-Identity with Potato spindle tuber viroid. Comptes rendus de l'Académie des Sciences Paris. 292:537-542.

Walter, B. 1987. Tomato apical stunt. Pages 321-326 in: The Viroids. T. O. Diener, ed. Plenum Press, New York, NY, USA.

Zhou, Y. C., Noussourou, M., Kon, T., Rojas, M. R., Jiang, H., Chen, L. F. Gamby, K., Foster, R., and Gilbertson, R. L. 2008. Evidence of local evolution of tomato-infecting begomovirus species in West Africa: Characterization of tomato leaf curl Mali virus and tomato yellow leaf crumple virus from Mali. Arch. Virol. 153:693-706. 